OPEN ACCESS

Edited by:

Joseph Eric Borovsky,

Space Science Institute, United States

Reviewed by:

Nickolay Ivchenko,

Royal Institute of Technology, Sweden

Roger Varney,

SRI International, United States

*Correspondence:

W. K. Peterson

bill.peterson@lasp.colorado.edu

Specialty section

This article was submitted to

Space Physics,

a section of the journal

Frontiers in Astronomy and Space

Sciences

Received: 18 January 2021

Accepted: 10 March 2021

Published: 09 April 2021

Citation:

Peterson WK (2021) Perspective on

Energetic and Thermal Atmospheric Photoelectrons.

Front. Astron. Space Sci. 8:655309. doi: 10.3389/fspas.2021.655309

\section{Perspective on Energetic and Thermal Atmospheric Photoelectrons}

\author{
W. K. Peterson* \\ Laboratory for Atmospheric and Space Physics, University of Colorado, Boulder, CO, United States
}

Atmospheric photoelectrons are central to the production of planetary ionospheres. They are created by photoionization of the neutral planetary atmosphere by solar EUV and soft X-ray irradiance. They provide the energy to heat the thermosphere. Thermalized photoelectrons permeate magnetospheres creating polarization electric fields and plasma waves as they interact with ions to maintain charge neutrality. Energetic photoelectrons $(>1 \mathrm{eV}$ ) have a distinctive energy spectral shape as first revealed in data from the Atmosphere Explorer satellites. Energetic photoelectrons escaping the ionosphere follow local magnetic fields illuminating the planet's magnetic topology. Current models using state-of-the-art EUV observations accurately capture their production and transport. However, in spite of 60 years of space research the electron thermalization processes occurring below $1 \mathrm{eV}$ at low altitudes in planetary thermospheres are not understood quantitatively. Results from event analysis of data from the Mars Atmosphere and Volatile Evolution (MAVEN) mission are not consistent with current models of photoelectron thermalization. The lack of quantitative understanding reflects the complexity of the physics and the lack of a large data base of simultaneous neutral, ion, and electron densities and temperatures in lower planetary thermospheres.

Keywords: photoelectrons, thermalization, ionization, ionosphere, Mars, Earth

\section{INTRODUCTION}

Electrons in the atmosphere were investigated by Chapman (1931) and by early radio scientists who inferred the existence of an ionized region surrounding the Earth created by the absorption of radiation from the sun. Early observations of the solar EUV irradiance (e.g., Rense, 1953) and atmospheric photoelectrons (e.g., Hinteregger et al., 1959) demonstrated the need for simultaneous, space based, observations of key ionospheric parameters over all local times and latitudes. NASA addressed this need in the early 1970's with the Atmosphere Explorer (AE) -C, -D, and -E satellites (Dalgarno et al., 1973). The AE satellites provided calibrated measurements of the solar EUV flux, the neutral atmosphere, and ionized components including atmospheric photoelectrons. These data supported the explosion of thermospheric research summarized in Schunk and Nagy (2009).

Current and planned NASA missions investigating planetary thermosheres are focused on understanding energy transport but do not directly address energy transfer associated with electron thermalization. The measurement techniques required to observe energetic $(>1 \mathrm{eV})$ and thermalized $\left(<10,000^{\circ} \mathrm{K}\right)$ photoelectrons have improved since AE. However, there is no systematic investigation of simultaneous in-situ electron fluxes spanning the energy range between energetic electrons measured by particle detectors and thermal electrons, measured by Langmuir probes or radars. 
I participated in the Atmosphere Explorer mission at the beginning of my career and the Mars Atmosphere and Volatile Evolution (MAVEN) mission to the Martian thermosphere near the end. Here I provide my perspective on observations and models of production, transport, and thermalization of atmospheric photoelectrons. Because of space limitations I'll focus primarily on published observations. The selection of data and models discussed is representative, not complete. Specifically, we do not address the optical observations such as those from NASA's GOLD satellite that use and test models of photoelectron production and transport (e.g., Solomon et al., 2020).

\section{OBSERVATIONS}

Figure 1 shows an overview of atmospheric photoelectron observations and selected model outputs from the AE (Dalgarno et al., 1973, inset panel B), Fast Auroral SnapshoT (FAST, Carlson et al., 1998a, inset panel C), and the MAVEN (Jakosky et al., 2015, panel A) satellites. The AE and FAST satellites sampled the Earth's ionosphere; the MAVEN satellite sampled the Martian ionosphere. Each panel shows electron flux in units of $\left(\mathrm{cm}^{2}-\mathrm{s}-\mathrm{sr}-\right.$ $\mathrm{eV})^{-1}$ as a function of energy in units of $\mathrm{eV}$. The MAVEN data shown in panel A cover the energy range from 0.01 to $1,000 \mathrm{eV}$ and the flux range from 1 to $10^{25}\left(\mathrm{~cm}^{2}-\mathrm{s}-\mathrm{sr}-\mathrm{eV}\right)^{-1}$, spanning both the thermal and energetic ranges. Panels $B$ and $C$ span sub sets of these ranges as indicated by the broad colored lines along the respective axes. In the next few paragraphs the data in Figure 1 are discussed in the order they were acquired, i.e., AE, FAST, and then MAVEN.

The AE-E data in panel $B$ are reproduced from Doering et al. (1976). The low altitude spectral features in the $20-30 \mathrm{eV}$ range are produced by the ionization of $\mathrm{O}$ and $\mathrm{N}_{2}$ into various energy states by the intense solar irradiance at $30.4 \mathrm{~nm}$. Doering et al.

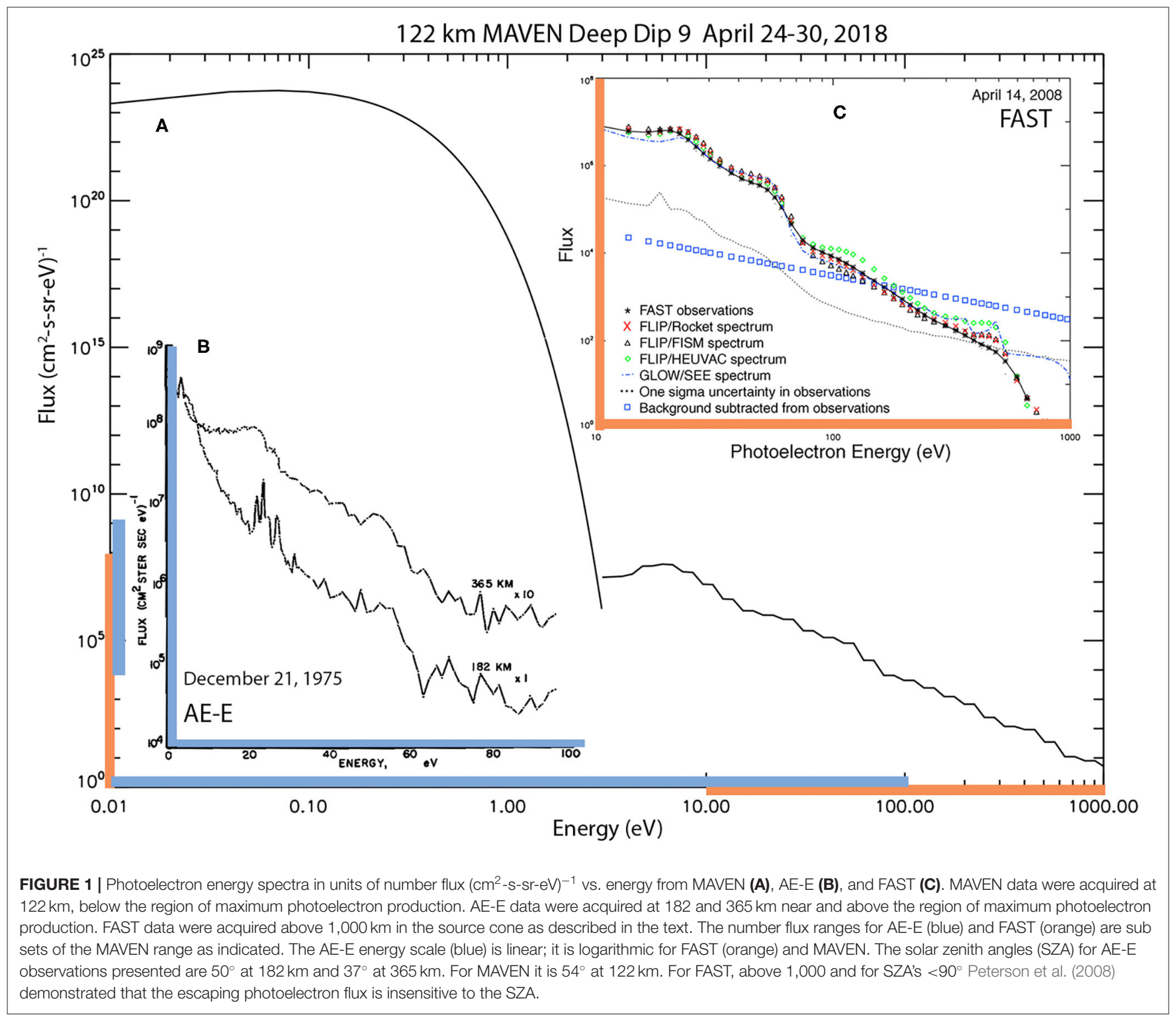


show that the strength of the emission features from $\mathrm{O}$ and $\mathrm{N}_{2}$ as a function of altitude follows the changes in both absolute density and composition. Doering noted that the $\sim 20-30 \mathrm{eV}$ features are smeared out at higher altitudes because the increasing fractional ionization enhances electron-electron collisions. He noted that there is a strong decrease in the spectrum near $60 \mathrm{eV}$ which we now know corresponds to a large decrease in solar irradiance below $\sim 16 \mathrm{~nm}$ (e.g., Woods et al., 2008). Doering et al. were able to determine the absolute spacecraft potential using energy resolved observations of the $20-30 \mathrm{eV}$ emission lines (Lee et al., 1978). A comprehensive summary of the photoelectron data obtained from the AE satellites was published by Lee et al. (1980a,b).

Above $60 \mathrm{eV}$ the signal in panel B is dominated by instrument noise. Winningham et al. (1989) extended the energy range of photoelectron observations to $\sim 1,000 \mathrm{eV}$ using a more sensitive electron spectrometer with coarser energy resolution. Thousand$\mathrm{eV}$ photoelectrons are produced by the solar soft X-ray flux near $1 \mathrm{~nm}$. Winningham et al. pointed out that the existing observations of the solar flux in the EUV and soft X-ray ranges were inconsistent with their photoelectron observations. This point will be addressed in the section addressing models below.

The data in panel $\mathrm{C}$ of Figure $\mathbf{1}$ are the daily averaged photoelectron flux measurements acquired above $1,000 \mathrm{~km}$ during apogee passes of the FAST satellite equatorward of the auroral zone on April 14, 2008 reproduced from Peterson et al. (2009). These data were acquired in the "source cone." Figure 2 illustrates the "source cone" concept. It displays data from one of the passes included in the average shown in panel $\mathrm{C}$ of Figure 1. The FAST electron analyzer has a $360^{\circ}$ field of view. The top panel in Figure 2 shows energy spectra averaged over all angles as a function of time. The bottom panel shows angular spectra averaged over the energy range of $100-12,000 \mathrm{eV}$. As noted above, the daily average photoelectron spectrum shown in Figure 1, Panel $\mathrm{C}$ does not include spectra obtained in the polar cap and auroral zone (such as before 19:17 UT in the orbit pass shown in Figure 2). The widest band in the lower panel, centered on $180^{\circ}$, is created by energetic photoelectrons produced in the ionosphere below the satellite. The angular width of the band is called the source cone. It is determined by the relative strengths of the magnetic field at the satellite and at the top of the ionosphere, respectively. A weaker band centered on $0^{\circ}$ is created by photoelectrons coming from the magnetically conjugate hemisphere (See, for example, Peterson et al., 1977a).

Note that the photoelectron flux in the source cone in units of $\left(\mathrm{cm}^{2}-\mathrm{s}-\mathrm{sr}-\mathrm{eV}\right)^{-1}$ above the ionosphere is independent of altitude because of magnetic focusing associated with the source cone formation, as the width of the source cone decreases while the area of the magnetic flux tube increases with increasing altitude. The narrow bands near 90 and $270^{\circ}$ come from photoelectrons produced on the spacecraft surface. The vertical bands between 19:20 and 19:25 UT are the noise signal produced by energetic ring current particles that penetrate instrumental shielding.

Peterson et al. (2009) assembled daily averaged photoelectron spectra from within the source cone, corrected individual spectra for spacecraft potential variations and the background from penetrating radiation. The solid black line in panel $\mathrm{C}$ of Figure 1 reports the daily average spectrum for April 14, 2008. The square boxes show the magnitude of the correction for penetrating radiation and the dotted line indicates the estimated one sigma uncertainty of the average spectrum shown. We defer discussion of the model results shown in panel $\mathrm{C}$ to the modeling section below.

The data in Figure 1, Panel A span 25 orders of magnitude in flux and 5 orders of magnitude in energy. They include thermal electrons with temperatures of $<1 \mathrm{eV}$ or $1.16 \cdot 10^{4}$ ${ }^{\circ} \mathrm{K}$. The electron data below $3 \mathrm{eV}$ were obtained at Mars from the Langmuir Probe and Waves (LPW) instrument on MAVEN (Andersson et al., 2015). They are presented as a Maxwellian distribution representing the average electron density $\left(1.2 \cdot 10^{5}\right.$ $\left.\mathrm{cm}^{-3}\right)$ and average electron temperature $\left(760{ }^{\circ} \mathrm{K}\right)$ observed between 120 and $125 \mathrm{~km}$ from April 24 to 30, 2018 during the deep dip \#9 interval (Peterson et al., 2020). Above $3 \mathrm{eV}$ the data are from the MAVEN Solar Wind Electron Analyzer (SWEA) instrument (Mitchell et al., 2016) averaged over the same intervals.

\section{GLOBAL INFORMATION OBTAINED FROM LOCALIZED PHOTOELECTRON OBSERVATIONS}

The energetic photoelectron energy spectrum is non-thermal and distinct from those found in the solar wind or the magnetosheath. The extremely intense solar $\mathrm{He} 30.4 \mathrm{~nm}$ irradiance produces narrow peaks in the $20-30 \mathrm{eV}$ range that are easily detected by instruments with sufficient energy resolution, as shown in panel $\mathrm{B}$ of Figure 1. Above $\sim 60 \mathrm{eV}$ the energy spectrum decreases by almost an order of magnitude corresponding to a decrease in the solar irradiance spectra at $\sim 15 \mathrm{~nm}$. At higher energies $(\sim 500 \mathrm{eV})$ emission peaks have been detected in the photoelectron spectra at Mars (Mitchell et al., 2000). These emission features are the result of the production of Auger electrons from atomic oxygen by soft $\mathrm{X}$ rays from the sun.

These distinct features in the photoelectron energy spectra allow investigators to use them to trace magnetic field lines, determine global magnetic topology, determine spacecraft potential, infer potential drops along magnetic field lines, and monitor variations in solar extreme ultraviolet (EUV) irradiance. Coates et al. (2011) and others have used instruments with high energy resolution in the $20-30 \mathrm{eV}$ range to identify photoelectrons at large distances from their sources on Venus, Mars, and Titan. Weber et al. (2020), Xu et al. (2019), and others have used instruments with higher sensitivity but coarser energy resolution than those used by Coates et al. to trace and explore the influences and dynamics associated with Martian crustal magnetic fields and their interaction with the solar wind magnetic field. Peterson et al. (1977a,b) used photoelectron energy spectra to identify photoelectrons originating in the magnetically conjugate hemisphere and place limits on the interhemispherical potential difference. Peterson et al. (2009, 2012) used photoelectrons to infer solar EUV and XUV energy input 


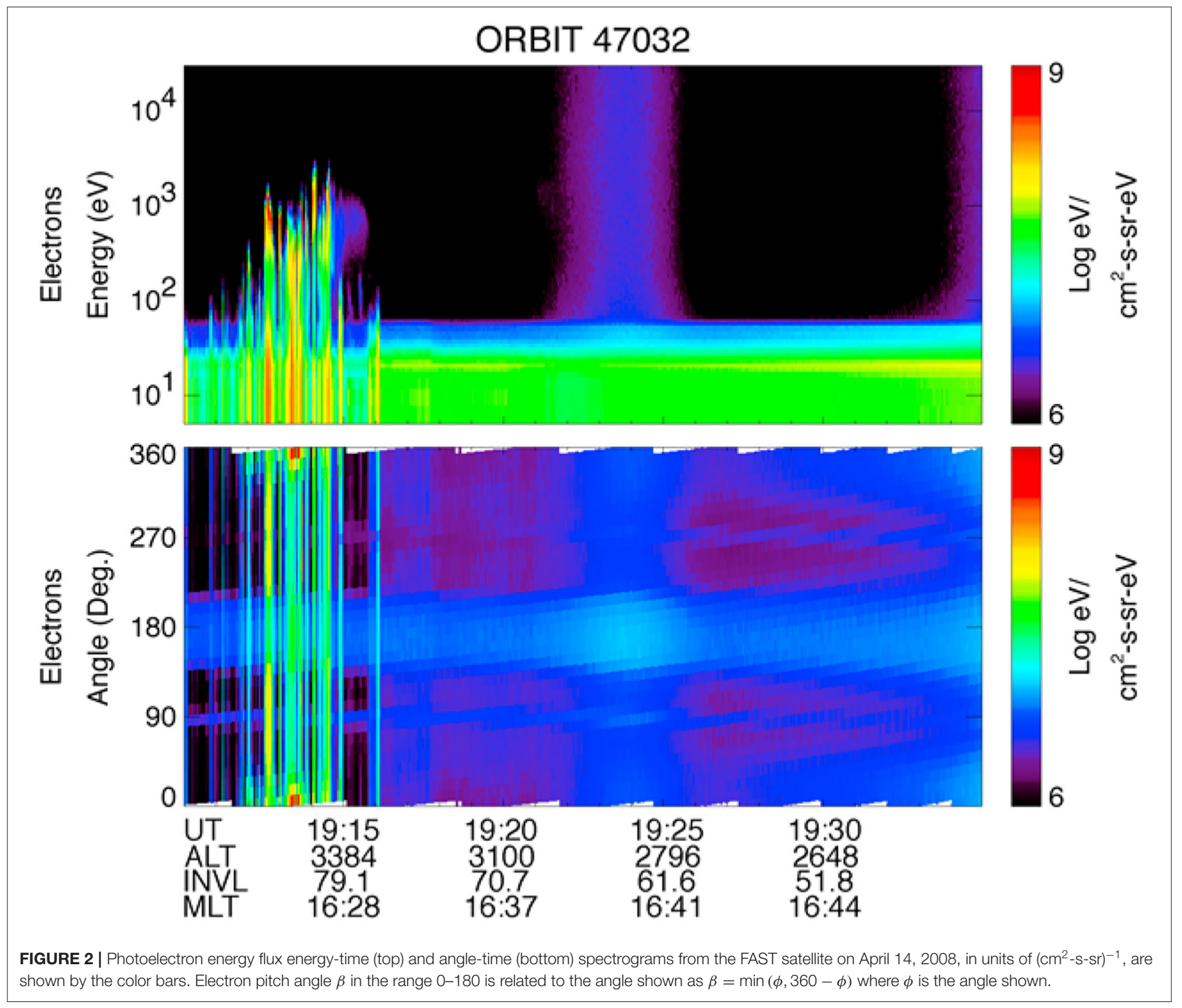

to the thermosphere on both solar flare and solar rotation time scales. Richards and Peterson (2008) directly measured the fraction of conjugate photoelectrons backscattered from the dark hemisphere.

\section{MODELS OF PHOTOELECTRON PRODUCTION, TRANSPORT, AND THERMALIZATION}

Initial comparisons of $\mathrm{AE}$ photoelectron fluxes and those calculated from AE neutral density and solar EUV measurements were presented by Nagy et al. (1977). Subsequent analysis by Richards and Torr (1984) demonstrated that the generally accepted EUV irradiance spectrum in 1984 (Heroux and Hinteregger, 1978) below $25 \mathrm{~nm}$ was inconsistent with observed photoelectron flux above $35 \mathrm{eV}$. Richards and Torr concluded that the Heroux and Hinteregger solar flux below $25 \mathrm{~nm}$ was about a factor of two too low. Modern measurements and models of the solar irradiance confirm the Richards and Torr assertion (e.g., Richards et al., 2006; Woods et al., 2008). The model/data comparisons shown in Figure 1, Panel C reproduced from Peterson et al. (2009) illustrate good agreement between observations and current models. The photoelectron models used were the Field Line Interhemispheric Plasma (FLIP) model (Richards et al., 2000) and the Global Airglow (GLOW) model (Solomon et al., 1988). The EUV model/data irradiance sets used as input to the models include a rocketborne calibration spectrum (Chamberlin et al., 2009), the Solar EUV Experiment (SEE) Version 9 reference spectrum (Woods et al., 2005), the Flare Irradiance Spectral Model (FISM; Chamberlin et al., 2007), and the High-resolution Solar EUV Model for Aeronomic Calculations (HEUVAC; Richards et al., 2006). 
The major differences between data and models of energetic photoelectrons now arise from the variability of the solar EUV irradiance, uncertainties in the observed or modeled neutral density from the Mass Spectrometer and Incoherent Scatter (MSIS) model (Hedin et al., 1977) and uncertainties in ionization cross sections, as well as observational uncertainties. McGranaghan et al. (2015) describe a publicly available model that is consistent with the photoelectron data shown in Figure 1, with the important caveat that the model has been validated in the low altitude range using electron density, not electron temperature profiles.

\section{THERMALIZATION OF ENERGETIC PHOTOELECTRONS}

Thermalized photoelectrons permeate planetary ionospheres and magnetospheres creating polarization electric fields (e.g., Axford, 1968) and plasma waves as they interact with ions to maintain charge neutrality (e.g., Borisov and Nielsen, 2005). They carry field aligned currents (e.g., Carlson et al., 1998b) and transfer energy via a heat flux between the ionosphere and magnetosphere (e.g., Kozyra et al., 1987; Khazanov et al., 2020).

Thermal electrons are created when photoelectron energy is transferred to ions and electrons. There have been too few simultaneous observations of thermal neutral, ion, and electron temperatures in the high-density region of a planetary thermosphere to confirm or refute the assumptions associated with photoelectron thermalization processes included in current models. However, recent results from the MAVEN spacecraft (Hanley et al., 2020; Peterson et al., 2020) have shown that the observed ion, neutral, and electron temperatures on Mars are not consistent with current models. In particular, Hanley et al. have measured ion temperatures using the MAVEN SupraThermal and Thermal Ion Composition (STATIC) instrument (McFadden et al., 2015). They demonstrated that during the MAVEN deep dip interval in October 2015, at the lowest altitudes sampled $(\sim 120 \mathrm{~km})$, the neutral $\left(110^{\circ} \mathrm{K}\right)$, ion $\left(250^{\circ} \mathrm{K}\right)$, and electron $(500$ $\left.{ }^{\circ} \mathrm{K}\right)$ temperatures were far from thermal equilibrium and warmer than expected.

\section{DISCUSSION}

The production and transport of energetic atmospheric photoelectrons are well-understood and accurately captured by current models using state-of-the-art EUV observations. Techniques have been developed to use the unique energy spectral shape of energetic photoelectrons to tease out details of planetary magnetic topology. However, in spite of 60 years of observations, the processes thermalizing photoelectrons at low altitudes in planetary thermospheres are not quantitatively understood. This lack of progress reflects the complexity of the physics and the lack of a data base of simultaneous neutral, ion, and electron temperatures at low altitudes to guide model development.

Current models of photoelectron thermalization are based on the heat equation which quantifies balance of electron heating and cooling (e.g., Matta et al., 2014). Thermalization occurs where the electron, ion, and neutral temperatures $\left(T_{E}, T_{I}, T_{N}\right)$ are equal. It is expected to occur in regions of high density and low fractional ionization. Existing models postulate an altitude (neutral density) where thermalization occurs. MAVEN observations of ion temperatures reported by Hanley et al. (2020) show that thermalization occurs on Mars at higher density $\left(>10^{11} \mathrm{~cm}^{-3}\right)$ and lower fractional ionization $(<2 \times$ $10^{-6}$ ) than expected. The analysis of observed electron and neutral temperatures presented in Peterson et al. (2020) suggests thermalization on Mars occurs below $100 \mathrm{~km}$ where the Bougher et al. (2015) model gives a density $\sim 10^{12} \mathrm{~cm}^{-3}$ and a fractional ionization of $\sim 10^{-8}$. Energetic photoelectron production by solar EUV and X-rays occurs well below Earth's mesopause $\left(\sim 80 \mathrm{~km}\right.$, density $>\sim 10^{14} \mathrm{~cm}^{-3}$ ) where it is strongly modulated by solar activity (e.g., Chamberlin et al., 2007).

Although the data base of incoherent radar ion and electron temperatures is vast, we are unaware of a large-scale data base of simultaneously obtained electron, ion, and neutral temperatures obtained in the Earth's thermosphere at densities $\sim>10^{12} \mathrm{~cm}^{-3}$. Such in-situ observations at Earth appear to be possible from satellites at altitudes as low as $100 \mathrm{~km}$ (neutral densities $\sim 10^{14}$ $\mathrm{cm}^{-3}$ and fractional ionization of $\sim 10^{-9}$ ) using state-of-theart- instruments and innovative spacecraft (Sarris et al., 2020; Palmroth et al., 2021). Observations below and above $100 \mathrm{~km}$ can be made from rockets.

Maven data and analysis show that current one-dimensional codes which use Maxwellian temperatures, empirical ion and electron temperature profiles, and relatively poorly determined cross sections do not adequately account for energy transfer between ions, neutrals, and electrons at the low temperatures and low altitudes below those that have been sampled on Earth and Mars. Deeper insights into the thermalization will require new observations and models. Relevant observations can be made from satellites and rockets as noted above. They can also be made in laboratory plasma chambers (Koepke, 2008). If sensitive enough diagnostics can be developed, the Enormus Toroidal Plasma Device (ETPD Cooper and Gekelman, 2013) could obtain definitive observations of how electrons, ions, and neutrals thermalize at high densities and low fractional ionization. However, it is more likely that large-scale kinetic codes which do not use assumed electron and ion temperature profiles will provide the needed new insights into the complex physics of electron thermalization.

\section{DATA AVAILABILITY STATEMENT}

All datasets presented in this study are included in the article/supplementary material.

\section{AUTHOR'S NOTE}

This paper summarizes what I've learned about thermal and energetic atmospheric photoelectrons since I first began investigating them in 1973. This paper examines the source of thermalized photoelectrons, demonstrates that we do not yet 
have a quantitative understanding of the thermalization process, and suggests how progress can be made.

\section{AUTHOR CONTRIBUTIONS}

The author confirms being the sole contributor of this work and has approved it for publication.

\section{REFERENCES}

Andersson, L., Ergun, R. E., Delory, G. T., Eriksson, A., Westfall, J., Reed, H., et al. (2015). The Langmuir Probe and Waves (LPW) instrument for MAVEN. Space Sci. Rev. 195, 173-198. doi: 10.1007/s11214-015-0194-3

Axford, W. I. (1968). The polar wind and the terrestrial helium budget. J. Geophys. Res. Sp. Phys. 73, 6855-6859. doi: 10.1029/JA073i021p06855

Borisov, N., and Nielsen, E. (2005). Excitation of plasma waves by unstable photoelectron and thermal electron populations on closed magnetic field lines in the Martian ionosphere. Ann. Geophys. 23, 1249-1258. doi: 10.5194/angeo-23-1249-2005

Bougher, S. W., Pawlowski, D., Bell, J. M., Nelli, S., McDunn, T., Murphy, J. R., et al. (2015). Mars global ionosphere-thermosphere model: solar cycle, seasonal, and diurnal variations of the mars upper atmosphere. J. Geophys. Res. Planets 120, 311-342. doi: 10.1002/2014JE004715

Carlson, C. W., McFadden, J. P., Ergun, R. E., Temerin, M., Peria, W., Mozer, F. S., et al. (1998b). FAST observations in the downward auroral current region: Energetic upgoing electron beams, parallel potential drops, and ion heating. Geophys. Res. Lett. 25, 2017-2020. doi: 10.1029/98GL00851

Carlson, C. W., Pfaff, R. F., and Watzin, J. C. (1998a). The Fast Auroral SnapshoT (FAST) mission. Geophys. Res. Lett. 25, 2013-2016. doi: 10.1029/98GL01592

Chamberlin, P. C., Woods, T. N., Crotser, D. A., Eparvier, F. G., Hock, R. A., and Woodraska, D. L. (2009). Solar cycle minimum measurements of the solar extreme ultraviolet (EUV) spectral irradiance on April 14, 2008. Geophys. Res. Lett. 36:L05102. doi: 10.1029/2008GL037145

Chamberlin, P. C., Woods, T. N., and Eparvier, G. F. (2007). Flare Irradiance Spectral Model (FISM): daily component algorithms and results. Space Weather 5:S07005. doi: 10.1029/2007SW000316

Chapman, S. (1931). The absorption and dissociative or ionizing effect of monochromatic radiation in an atmosphere on a rotating earth. Proc. Phys. Soc. London 43, 26-45, 483-501. doi: 10.1088/0959-5309/43/5/302

Coates, A. J., Tsang, S. M. E., Wellbrock, A., Frahm, R. A., Winningham, J. D., Barabash, S., et al. (2011). Atmospheric photoelectrons: comparing Venus, Earth, Mars, and Titan. Planet. Space Sci. 59, 1019-1027. doi: 10.1016/j.pss.2010.07.016

Cooper, C. M., and Gekelman, W. (2013). Termination of a magnetized plasma on a neutral gas: the end of the plasma. Phys. Rev. Lett. 110:265001. doi: 10.1103/PhysRevLett.110.265001

Dalgarno, A., Hanson, W. B., Spencer, N. W., and Schmerling, E. R. (1973). The atmosphere explorer mission. Radio Sci. 8, 263-266. doi: 10.1029/RS008i004p00263

Doering, J. P., Peterson, W. K., Bostrom, C. O., and Potemra, T. A. (1976). High resolution daytime photoelectron energy spectra from AE-E. Geophys. Res. Lett. 3, 129-131. doi: 10.1029/GL003i003p00129

Hanley, K. G., Mitchell, D. L., McFadden, J. P., Fowler, C. M., Stone, S. W., Pilinski, M., et. al. (2020). "O ${ }_{2}^{+}$temperature profiles measured by MAVEN STATIC", in P049-06 presented at 2020 Fall Meeting, AGU, 1-17 Dec (San Francisco, CA). doi: 10.5194/epsc2020-349

Hedin, A. E., Salah, E., Evand, J. V., Reber, C. A., Newton, G. P., Spencer, N. W., et al. (1977). A global thermospheric model based on mass spectrometer and incoherent scatter data, MSIS $1 . \mathrm{N}_{2}$ density and temperature. J. Geophys. Res. 82, 2139-2147. doi: 10.1029/JA082i016p02148

Heroux, L., and Hinteregger, H. E. (1978). Aeronomical reference spectrum for solarUV below $2000 \mathrm{~A}^{\circ}$. J. Geophys. Res. 8, 5305-5308. doi: 10.1029/JA083iA11p05305

\section{ACKNOWLEDGMENTS}

WKP thanks Gwen Hanley for sharing her preliminary ion temperature observations from the MAVEN spacecraft, Phil Richards for re-igniting my interest in atmospheric photoelectrons, and Andrew Yau and Mark Koepke for insightful comments on an early version of this paper.

Hinteregger, H. E., Damon, K. R., and Hall, L. A. (1959). Analysis of photoelectrons from solar extreme ultraviolet. J. Geophys. Res. 64, 961-969. doi: 10.1029/JZ064i008p00961

Jakosky, B. M., Lin, R. P., and Zurek, R. (2015). The Mars Atmosphere and Volatile Evolution (MAVEN) mission. Space Sci. Rev. 195, 3-48. doi: 10.1007/s11214-015-0221-4

Khazanov, G. V., Glocer, A., and Chu, M. (2020). The formation of electron heat flux in the region of diffuse aurora. J. Geophys. Res. 125:e2020JA028175. doi: 10.1029/2020JA028175

Koepke, M. E. (2008). Interrelated laboratory and space plasma experiments. Rev. Geophys. 46:RG3001. doi: 10.1029/2005RG000168

Kozyra, J. U., Shelley, E. G., Comfort, R. H., Brace, L. H., Cravens, T. E., and Nagy, A. F. (1987). The role of ring current $\mathrm{O}^{+}$in the formation of stable auroral red arcs. J. Geophys. Res. 92, 7487- 7502. doi: 10.1029/JA092iA07p07487

Lee, J. S., Doering, J. P., Bostrom, C. O., and Potemra, T. A. (1978). Measurement of the daytime photoelectron energy distribution from AEE with improved energy resolution. Geophys. Res. Lett. 5, 581-583. doi: 10.1029/GL005i007p00581

Lee, J. S., Doering, J. P., Potemra, T. A., and Brace, L. H. (1980a). Measurements of the ambient photoelectron spectrum from Atmosphere Explorer: I. AE-E measurements below $300 \mathrm{~km}$ during solar minimum conditions. Planet. Sp. Sci. 28, 947-971. doi: 10.1016/0032-0633(80)90058-6

Lee, J. S., Doering, J. P., Potemra, T. A., and Brace, L. H. (1980b). Measurements of the ambient photoelectron spectrum from Atmosphere Explorer: II. AE-E measurements from 300 to $1000 \mathrm{~km}$ during solar minimum conditions. Planet. Sp. Sci. 28, 973-996. doi: 10.1016/0032-0633(80)90059-8

Matta, M., Galand, M., Moore, L., Mendillo, M., and Withers, P. (2014). Numerical simulations of ion and electron temperatures in the ionosphere of Mars: multiple ions and diurnal variations. Icarus 227, 78-88. doi: 10.1016/j.icarus.2013.09.006

McFadden, J. P., Kortmann, O., Curtis, D., Dalton, G., Johnson, G., Abiad, R., et al. (2015). MAVEN SupraThermal and Thermal Ion Composition (STATIC) instrument. Space Sci. Rev. 195,199-256. doi: 10.1007/s11214-015-0175-6

McGranaghan, R., Knipp, D. J., Solomon, S. C., and Fang, X. (2015). A fast, parameterized model of upper atmospheric ionization rates, chemistry, and conductivity. J. Geophys. Res. Space Phys. 120, 4936-4949. doi: 10.1002/2015JA021146

Mitchell, D. L., Lin, R. P., Rème, H., Crider, D. H., Cloutier, P. A., Connerney, J. E. P., et. al. (2000). Oxygen Auger electrons observed in Mars' ionosphere. Geophys. Res. Lett. 27, 1871-1874. doi: 10.1029/1999GL 010754

Mitchell, D. L., Mazell, C., Sauvaud, J.-A., Thocaven, J.-J., Rouzaud, J., Fedorov, A., et al. (2016). The MAVEN Solar Wind Electron Analyzer (SWEA). Space Sci. Rev. 200, 495-528. doi: 10.1007/s11214-015-0232-1

Nagy, A. F., Doering, J. P., Peterson, W. K., Torr, M. R., and Banks, P. M. (1977). Comparison between calculated and measured photoelectron fluxes from Atmosphere Explorer C and E. J. Geophys. Res. 82, 5099-5103. doi: 10.1029/JA082i032p05099

Palmroth, M., Grandin, M., Sarris, T., Doornbos, E., Tourgaldis, S., Aikio, A., et al. (2021). Lower-thermsphere-ionosphere (LTI) quantities: current status of measuring techniques and models. Ann. Geophys. 49, 189-237. doi: 10.5194/angeo-39-189-2021

Peterson, W. K., Andersson, L., Ergun, R., Thiemann, E., Pilinski, M., Thaller, S., et al. (2020). Subsolar electron temperatures in the lower Martiionosphere. J. Geophys. Res. 125:e2019JA027597. doi: 10.1029/2019JA027597 
Peterson, W. K., Doering, J. P., Potemra, T. A., Brace, L. H., Heelis, R. A., and Hanson, W. B. (1977b). Measurement of magnetic field aligned potential differences using high resolution conjugate photoelectron energy spectra. Geophys. Res. Lett. 4, 373-376. doi: 10.1029/GL004i009p00373

Peterson, W. K., Doering, J. P., Potemra, T. A., McEntire, R. W., and Bostrom, C. O. (1977a). Conjugate photoelectron fluxes observed on Atmosphere Explorer C. Geophys. Res. Lett. 4, 109-112. doi: 10.1029/GL004i003p00109

Peterson, W. K., Stavros, E. N., Richards, P. G., Chamberlin, P. C., Woods, T. N., Bailey, S. M., et al. (2009). Photoelectrons as a tool to evaluate spectral variations in solar EUV irradiance over solar cycle timescales. J. Geophys. Res. 114:A10304. doi: 10.1029/2009JA014362

Peterson, W. K., Woods, T. N., Chamberlin, P. C., and Richards, G. P. (2008). Photoelectron flux variations observed from the FAST satellite. Adv. Space Res. 42, 947-956. doi: 10.1016/j.asr.2007.08.038

Peterson, W. K., Woods, T. N., Fontenla, J. M., Richards, P. G., Chamberlin, P. C., Solomon, S. C., et al. (2012). Solar EUV and XUV energy input to thermosphere on solar rotation time scales derived from photoelectron observations. J. Geophys. Res. 117:A05320. doi: 10.1029/2011JA017382

Rense, W. A. (1953). Intensity of Lyman-alpha line in the solar spectrum. Phys. Rev. 91,229-302. doi: 10.1103/PhysRev.91.299

Richards, P. G., Buonsanto, M. J., Reinisch, B. W., Holt, J., Fennelly, J. A., Scali, J. L., et al. (2000). On the relative importance of convection and temperature on the behavior of the ionosphere in North America during January 6-12, 1997. J. Geophys. Res. 105, 12763-12776. doi: 10.1029/1999JA000253

Richards, P. G., and Peterson, K. W. (2008). Measured and modeled backscatter of ionospheric photoelectron fluxes. J. Geophys. Res. 113:A08321. doi: 10.1029/2008JA013092

Richards, P. G., and Torr, D. G. (1984). An investigation of the consistency of ionospheric measurements of the photoelectron flux and solar EUV flux. J. Geophys. Res. 89, 5625-5635. doi: 10.1029/JA089iA07p05625

Richards, P. G., Woods, T. N., and Peterson, W. K. (2006). HEUVAC: a new high resolution solar EUV proxy model. Adv. Sp. Res. 37, 315-322. doi: 10.1016/j.asr.2005.06.031

Sarris, T. E., Talaat, E. R., Palmroth, M., Dandouras, I., Armandillo, E., Kervalishvili, G., et al. (2020). Daedalus: a low-flying spacecraft for in situ exploration of the lower thermosphere-ionosphere. Geosci. Instrum. Method. Data. Syst. 9, 153-191. doi: 10.5194/gi-9-153-2020

Schunk, R., and Nagy, A. (2009). Ionospheres: Physics, Plasma Physics, and Chemistry (2nd ed., Cambridge Atmospheric and Space Science Series).
Cambridge: Cambridge University Press. doi: 10.1017/CBO97805116 35342

Solomon, S. C., Andersson, L., Burns, A. G., Eastes, R. W., Martinis, C., McClintock, W. E., et al. (2020). Global scale observations and modeling of far ultraviolet airglow during twilight. J. Geophys. Res. 125:e2019JA027645. doi: 10.1029/2019JA027645

Solomon, S. C., Hays, P. B., and Abreu, J. V. (1988). The auroral 6300A emission: observations and modeling. J. Geophys. Res. 93, 9867-9882. doi: 10.1029/JA093iA09p09867

Weber, T., Brain, D., Xu, S., Mitchell, D., Espley, J., Halekas, J., et al. (2020). The influence of interplanetary magnetic field direction on Martian crustal magnetic field topology. Geophys. Res. Lett. 47:e2020GL087757. doi: 10.1029/2020GL087757

Winningham, J. D., Decker, D. T., Kozyra, J. U., and Nagy, A. F., Jasperse, J.R. (1989). Energetic ( $>60 \mathrm{eV}$ ) atmospheric photoelectrons. J. Geophys. Res. 94, 15335-15348. doi: 10.1029/JA094iA11p15335

Woods, T. N., Chamberlin, P. C., Peterson, W. K., Meier, R. R., Richards, P. G., Strickland, D. J., et al. (2008). XUV Photometer System (XPS): improved solar irradiance algorithm using CHIANTI spectral models. Solar Phys. 250, 235-267. doi: 10.1007/s11207-008-9196-6

Woods, T. N., Eparvier, F. G., Bailey, S. M., Chamberlin, P. C., Lean, J., Rottman, G. J., et al. (2005). The solar EUV Experiment (SEE): mission overview and first results. J. Geophys. Res. 110:A01312. doi: 10.1029/2004JA 010765

Xu, S., Weber, T., Mitchell, D. L., Brain, D. A., Mazelle, C., DiBraccio,G. A., et al. (2019). A technique to infer magnetic topology at Mars and its application to the terminator region. J. Geophys. Res. 124, 1823-1842. doi: 10.1029/2018JA026366

Conflict of Interest: The author declares that the research was conducted in the absence of any commercial or financial relationships that could be construed as a potential conflict of interest.

Copyright (c) 2021 Peterson. This is an open-access article distributed under the terms of the Creative Commons Attribution License (CC BY). The use, distribution or reproduction in other forums is permitted, provided the original author(s) and the copyright owner(s) are credited and that the original publication in this journal is cited, in accordance with accepted academic practice. No use, distribution or reproduction is permitted which does not comply with these terms. 